\title{
A diplomacia cultural entre Brasil e Argentina (1930-1954)
}

\author{
Rodolpho Gauthier Cardoso dos Santos ${ }^{1}$
}

SANTOS, Raquel Paz dos. Um novo olhar sobre o país vizinho. A cooperação cultural como crítica ao paradigma da rivalidade no contexto das relações Brasil-Argentina (1930-1954). Rio de Janeiro: Editora Multifoco, 2012, 265 p.

Resenha recebida em: $31 / 08 / 2014$

Resenha aprovada para publicação em: 19/11/2014

O trabalho da historiadora Raquel Paz dos Santos traz contribuições aos que se dedicam a pensar um tema sempre atual: as relações entre Brasil e Argentina. Fruto de uma tese de doutorado defendida em 2008 na Universidade Federal Fluminense (UFF), o livro tem como recorte temporal os anos de 1930 a 1954. A pesquisadora lança luz especialmente sobre as iniciativas de colaboração cultural entre os dois países nesse período. Como alertado por ela, esse objeto foi, em comparação às relações políticas, econômicas e militares, um tanto quanto negligenciado pelos pesquisadores das Ciências Humanas.

Após a Primeira Guerra Mundial, houve, de modo geral, intensificação dos gastos dos Estados nacionais com ações de política externa que redundassem em aproximação cultural com outros povos. Para além dos objetivos econômicos, interessava a divulgação de uma imagem positiva dos países junto à opinião pública de outras nações, de modo a fortalecer laços, especialmente com os meios intelectuais e quadros dirigentes (2012, p. 41). Como demonstrado pela autora, essa preocupação desenvolveu-se no Brasil e na Argentina sobretudo a partir da década de 1930, quando se estruturaram oficialmente os setores culturais dos serviços diplomáticos dos respectivos países.

A ideia central do livro, discutida no primeiro capítulo, é a crítica ao que a autora chama de "paradigma da rivalidade", ou seja, a proposta de analisar as relações entre Brasil

\footnotetext{
${ }^{1}$ Doutorando em História pela USP (Universidade de São Paulo) e professor do IFMG (Instituto Federal de Minas Gerais). Desenvolve pesquisa com título Da República Sindicalista ao Pacto ABC: o antiperonismo na imprensa conservadora brasileira (1945-1955). E-mail: rodolpho.santos@ifmg.edu.br
}

\section{GANPHLAC}

Revista Eletrônica da ANPHLAC, ISSN 1679-1061, Nº. 17, p. 362-367, jul./dez. 2014. http://revista.anphlac.org.br/ 
e Argentina como pautadas historicamente e de modo inescapável pela competição e desconfiança. Nesse sentido, ela elenca pesquisadores que, em maior ou menor grau, teriam feito uma análise com tal abordagem. Segundo ela, estudiosos importantes das relações internacionais, como Stanley Hilton, Miguel Angel Scena, Moniz Bandeira, Jorge Hugo Herrera, Amado Luis Cervo e Mônica Hirst teriam valorizado mais a competição do que a cooperação. Dessa forma, teriam ignorado especialmente as tentativas de colaboração e aproximação cultural ocorridas. Segundo a autora (p. 35), “essa produção [acadêmica] se nutre desse imaginário [de rivalidade intrínseca] e o reforça, se tornando um constructo resistente à crítica".

No lugar da abordagem mais focada em questões políticas, militares e econômicas, Raquel Paz dos Santos propõe, a partir das concepções teóricas de autores como Lorenzo Delgado Gomez-Escalonila e Ricardo D. Salvatore, que as relações entre os dois países sejam observadas pela ótica da cooperação cultural. Para isso, a historiadora analisou principalmente as correspondências dos embaixadores do Brasil e da Argentina. Tal material encontra-se disponível nos arquivos do Itamaraty, no Rio de Janeiro, e no Archivo General de la Cancillería Argentina, em Buenos Aires.

Ao constatar que a colaboração cultural não foi feita apenas por agentes estatais, mas também por artistas, intelectuais, acadêmicos e diferentes elementos da sociedade civil, a autora ampliou a busca por referências em outros tipos de acervo. Assim, consultou também arquivos e bibliotecas de institutos culturais, de museus de arte, de escolas, de academias de medicina e outros arquivos e hemerotecas das duas nações.

O exame desse vasto material inicia-se no segundo capítulo, dedicado a analisar as representações sobre a Argentina e os argentinos, construídas pelos embaixadores brasileiros em Buenos Aires. Trata-se de uma proposta ambiciosa, se consideramos a imensa quantidade de fontes produzidas pelos diferentes diplomatas nos anos em questão. ${ }^{2}$ A autora inicialmente detalha a construção do processo de cooperação cultural do serviço diplomático brasileiro durante a Era Vargas (p. 54-61) e, em seguida, escolhe para análise apenas alguns informes e pronunciamentos que tratam principalmente de intercâmbios culturais.

\footnotetext{
${ }^{2}$ Na seleção dos documentos, foram privilegiados os anos de 1930, 1933 a 1937, 1943 a 1946 e 1951 a 1954.

\section{GANPHLAC}

Revista Eletrônica da ANPHLAC, ISSN 1679-1061, Nº. 17, p. 362-367, jul./dez. 2014. http://revista.anphlac.org.br/
} 
De acordo com ela (p. 87), as oscilações das relações políticas e econômicas entre os dois países interferiram em alguns momentos no fluxo de trocas culturais promovidas pelos Estados nacionais. Mesmo nesses períodos, porém, a atuação dos embaixadores brasileiros como mediadores teria combatido preconceitos e buscado a aproximação entre os dois povos através do estímulo aos diferentes tipos de intercâmbio (p. 104).

Nesse capítulo, seria importante examinar mais a fundo as principais representações expressas nessas fontes, levando-se em consideração, em especial, o pensamento e a biografia de cada um dos embaixadores. Pensar a diplomacia brasileira como um corpo não homogêneo de ideias e de pessoas pode ajudar a compreender momentos de tensão que, se não foram perenes, também foram importantes. É o caso, por exemplo, das críticas que, malgrado sua atuação, o Itamaraty sofreu por parte de Juan Domingo Perón em 1953. Para o mandatário argentino, o Itamaraty atuava como órgão "supragovernamental" e deveria ser desmontado porque atrapalhava a integração entre as duas nações (BANDEIRA, 2010, p. 260).

No terceiro capítulo, a proposta da autora inverte-se. Desta vez, preocupa-se com o exame das representações construídas pelos diplomatas argentinos a respeito do Brasil. Novamente, a tarefa apresenta-se hercúlea. Como solução, a historiadora opta por analisar algumas fontes selecionadas que foram produzidas pelos diferentes funcionários da chancelaria no Rio de Janeiro. Outra vez, ela busca demonstrar o esforço dos embaixadores em "combater a imagem da rivalidade e colocar outra em seu lugar, buscando, através do seu papel de mediador, produzir interpretações da realidade para além das visões impregnadas de estereótipos" (p. 125-126).

É compreensível que, nos pronunciamentos públicos, o jogo retórico diplomático que evoca a irmandade latino-americana predomine dos dois lados. No entanto, outras visões surgem da correspondência oficial privada levantada pela própria autora. É caso, por exemplo, de Julio Iglesias, adido cultural da embaixada no Rio de Janeiro, que afirma que "ao brasileiro, lhe interessa o superficial e o brilhante: fantasiar e não meditar (...)" (p. 151). Ou de Nicolas C. Accame, embaixador argentino em 1946, que atribui à descendência portuguesa e africana um suposto complexo de inferioridade do povo brasileiro (p. 156). Mais exemplos de informes pontilhados por preconceitos e

\section{CANPHLAC}

Revista Eletrônica da ANPHLAC, ISSN 1679-1061, Nº. 17, p. 362-367, jul./dez. 2014. http://revista.anphlac.org.br/ 
incompreensões podem ser encontrados em fontes diplomáticas da época, transcritas pelo jornalista Hamilton Almeida (2005). ${ }^{3}$ Tais documentos mostram que a ideia romântica do diplomata, de qualquer país, como ser profundamente aberto ao outro e dotado de uma visão culturalmente mais tolerante pode, algumas vezes, estar longe da realidade.

Deve-se levar em conta também a existência no ofício do diplomata de uma situação, aparentemente contraditória, que consiste, de um lado, em buscar a aproximação cultural e, por outro, postergar/dificultar acordos de colaboração e estreitamento político mais profundos. ${ }^{4}$ Foi o que ocorreu com o Itamaraty durante os anos do governo Dutra (1946-1951). Longe dos olhos do público, essa atuação ambígua foi, aparentemente, bastante comum nas embaixadas, o que ajuda a entender algumas tensões perceptíveis nos informes trocados reservadamente.

É importante salientar, especialmente, o quarto e último capítulo, quando a historiadora apresenta um excelente mapeamento das dezenas de iniciativas de intercâmbio cultural entre os dois países no período. São descritos diversos tipos de empreendimentos culturais importantes, como edições de livros, exposições de artes, intercâmbios entre museus e sociedades científicas, construção de institutos culturais e de monumentos, atividades ligadas ao pan-americanismo escolar e missões de estudantes, professores de universidades, artistas (escultores, pintores, músicos e atores) e sindicalistas. ${ }^{5}$

Raquel Paz dos Santos destaca também a integração entre os ministérios das Relações Exteriores e da Educação do Brasil no desenvolvimento e execução de projetos de intercâmbio cultural. Assinala ainda a participação de intelectuais, como Gilberto Freyre, na formulação dessas políticas. A adesão deles, de acordo com a autora, não foi manipulada pelo Estado, mas “(...) espontânea e, por outro lado, também interessada, pois,

\footnotetext{
${ }^{3}$ Ao comentar sobre a situação do Partido Comunista Brasileiro, por exemplo, um informe da embaixada argentina nos anos 1950 afirmou: "No entanto, talvez a principal defesa contra o comunismo neste país seja a passividade da grande maioria da população. O seu caráter submisso - produto da mistura de raças, do clima e de reminiscências da época da escravidão - dificulta a propaganda. Sua mansidão e apatia tradicionais são freios que se opõem à organização e à atividade agressiva característica dessa ideologia". (ALMEIDA, 2005, p. 258-259)

${ }^{4}$ Nesse sentido, o trabalho do historiador Iuri Cavlak também é muito importante, pois mostra correspondência de embaixadores brasileiros na Argentina que eram nitidamente antiperonistas (CAVLAK, 2008).

${ }^{5}$ Também existiram iniciativas de cooperação esportivas, tais como os Jogos Pan-Americanos de Buenos Aires em 1951, que são citadas brevemente no trabalho e mereceriam um estudo de caso específico em trabalho posterior.
}

\section{GANPHLAC}

Revista Eletrônica da ANPHLAC, ISSN 1679-1061, N. 17, p. 362-367, jul./dez. 2014. http://revista.anphlac.org.br/ 
através dela, poderiam obter os recursos financeiros e operacionais de que não dispunham para desenvolver seus projetos" (p. 194).

Esse levantamento geral de tais iniciativas é bastante importante e pode contribuir para trabalhos acadêmicos futuros que analisem casos específicos, como, por exemplo, a interação entre artistas plásticos brasileiros e argentinos nos anos 1930. Outro campo que parece pouco explorado em pesquisas historiográficas é o intercâmbio entre as sociedades médicas das duas nações que colaboraram em pesquisas conduzidas conjuntamente (p. 222). Também interessantes seriam investigações que garimpassem um número maior de documentos sobre a atuação dos polêmicos adidos operários estabelecidos pelo peronismo no Brasil e em outros países (PANELLA, 1994).

Assim, a obra indica, através de novas fontes, muitos caminhos de pesquisa aparentemente profícuos e até pouco tempo desconhecidos. Ao trazer à tona um objeto historiográfico até então relativamente eclipsado, a cooperação cultural, o livro lança luz sobre novos temas, documentos e questões que, principalmente no campo da história cultural, poderão ser exploradas aprofundadamente em trabalhos acadêmicos futuros.

Do nosso ponto de vista, a obra de Raquel Paz dos Santos complementa análises acadêmicas anteriores também importantes que comprovaram, através de muitos documentos, a existência de relações pautadas pela rivalidade e competição que iam além do imaginário. Observada em perspectiva com as fontes citadas nesses outros trabalhos, a documentação levantada pela historiadora indica que cooperação e rivalidade conviveram contraditoriamente nas oscilantes relações entre as duas sociedades e seus serviços diplomáticos.

Em tempos de rivalidade exacerbada e reforço de antigos estereótipos, como na recente Copa do Mundo de 2014, essa lembrança de que a história entre Brasil e Argentina também foi feita por aproximações e compreensão mútua ganha especial importância política.

\section{GANPHLAC}

Revista Eletrônica da ANPHLAC, ISSN 1679-1061, Nº. 17, p. 362-367, jul./dez. 2014. http://revista.anphlac.org.br/ 


\section{Referências Bibliográficas}

ALMEIDA, B. Hamilton. Sob os olhos de Perón: o Brasil de Vargas e as relações com a Argentina. Rio de Janeiro: Record, 2005.

CAVLAK, Iuri. A política externa brasileira e a Argentina peronista (1946-1955). São Paulo: Annablume, 2008.

MONIZ BANDEIRA, Luiz Alberto. Brasil, Argentina e Estados Unidos: conflito e integração na América do Sul (da Tríplice Aliança ao Mercosul), 1870-2007. $3^{\mathrm{a}}$ edição revisada e ampliada. Rio de Janeiro: Civilização Brasileira, 2010.

PANELLA, Claudio. Los agregados obreros. Revista Todo es Historia, n. 328, octubre 1994.

\section{GANPHLAC}

Revista Eletrônica da ANPHLAC, ISSN 1679-1061, Nº 17, p. 362-367, jul./dez. 2014.

http://revista.anphlac.org.br/ 